\title{
Perancangan Augmented Reality Media Edukasi Protokol Kesehatan Berbasis Permainan Papan
}

\author{
Didit Prasetyo $^{1}$, Octaviyanti Dwi Wahyurini ${ }^{2}$ \\ ${ }^{1}$ Departemen Desain Komunikasi Visual ITS Surabaya \\ Gedung Desain, Kampus ITS Sukolilo Surabaya, e-mail: didit@its.ac.id \\ ${ }^{2}$ Departemen Desain Komunikasi Visual ITS Surabaya \\ Gedung Desain, Kampus ITS Sukolilo Surabaya, e-mail: oyndwi@prodes.its.ac.id
}

\section{ARTICLE INFO}

Article history:

Received

Received in revised form

Accepted

Available online

\section{ABSTRACT}

Palagan is the name of a board game with a type of card game that has been distributed in the East Java region since the end of 2020 where the game is connected in one big narrative regarding the education of Covid-19 prevention behavior protocols equipped with attractive visual illustrations, Palagan is equipped with an Augmented Reality application as a complementary feature where the advantage is that it can arouse the interest of its users to learn and can make its users feel entertained, the contribution of this research is to map augmented reality content with the theme of health protocol education which is specifically intended for elementary school-aged children as an effort to minimize the gap in the level of compliance with the application health protocols in the community in urban areas.

Keywords: augmented reality, health protocols, school-aged

\section{Pendahuluan}

Di Indonesia sejak masa pandemi melanda, pemerintah memberi himbauan kepada masyarakat untuk menjalankan protokol kesehatan guna mengantisipasi penularan wabah COVID-19 melalui beberapa aktivitas, kegiatan protokol kesehatan itu diantaranya adalah mencuci tangan menggunakan sabun dan membilasnya dengan air mengalir, protokol berikutnya menghindari memegang semua bagian wajah sebelum mencuci tangan, mencuci tangan sebelum masuk ditempat kerja, ketika ditempat umum dan sebelum masuk rumah sehabis berkegiatan diluar rumah, dapat menggunakan hand sanitizer jika tidak ada air disekitar, protokol selanjutnya adalah wajib mengenakan masker bila keluar rumah atau ditempat umum, berikutnya menerapkan etika batuk dengan menutup mulut ketika batuk atau bersin atau jika tidak mengenakan masker, selalu mencuci tangan setelah etika batuk, protokol berikutnya adalah menghindari keramaian dan jika ditempat umum berusaha menjaga jarak minimal 1 meter dengan orang disekitarnya (physical distancing), protokol berikutnya lebih memilih berada dirumah atau tidak bepergian kecuali keadaan mendesak, protokol selanjutnya segera ke rumah sakit untuk dilakukan pemeriksaan jika merasakan gejala COVID 19[1].

Berbeda dengan harapan dari himbauan penerapan protokol kesehatan, dalam keseharian masyarakat terdapat kepatuhan dan keabaian terhadap penerapan protokol kesehatan, 72\% kepatuhan banyak dilakukan oleh masyarakat berusia dewasa dibanding usia remaja atau anakanak dan 69\% dilakukan oleh masyarakat dengan pendidikan lebih tinggi (menengah-atas)[2] 
dimana hal ini menunjukkan adanya kesenjangan kepatuhan pada masyarakat berusia anak-anak atau pendidikan dasar. Pendidikan penanggulangan dan pencegahan suatu kondisi bencana atau pandemi sangat diperlukan bagi anak-anak yang menjadi segmentasi paling rentan dan terdampak secara psikologis apabila bencana tersebut terjadi [3]. Dalam rangka untuk meminimalisir kesenjangan tingkat kepatuhan penerapan protokol kesehatan diperlukan pendekatan komunikasi terhadap anak-anak, pendekatan media komunikasi yang sesuai untuk mengenalkan dan membiasakan protokol kesehatan adalah media yang biasa digunakan oleh anak-anak ketika berada ditengah aktivitas keluarga atau dengan usia sebayanya yang salah satunya adalah permainan papan (boardgame). Melalui media pembelajaran yang menggunakan basis permainan, anak-anak mendapat ilmu berupa teori dan juga praktek yang berwujud pengalaman secara tidak langsung, pembelajaran berbasis permainan ini dinilai mampu memberikan dan meningkatkan kreatifitas untuk anak-anak. Dengan media komunikasi berupa permainan, kinerja motorik anakanak dapat ditingkatkan sehingga dapat berpikir dan bertindak dengan benar dalam satu waktu [4].

Sejak tahun 2020 telah diluncurkan permainan papan berjudul Palagan, Palagan merupakan permainan papan dengan jenis kartu permainan yang terdiri dari 7 komponen kartu elemen yang terkoneksikan dalam satu narasi besar mengenai edukasi protokol perilaku pencegahan covid-19 yang dilengkapi ilustrasi visual yang menarik [5], boardgame ini terdiri dari elemen kartu informasi gizi seimbang, kartu protokol kesehatan, kartu olahraga, kartu peristiwa gambaran sehari-hari saat pandemi, kartu bahaya peringatan tentang kegiatan yang tidak boleh dilakukan, kartu kebaikan yang berisi anjuran kegiatan untuk dilakukan dan kartu proteksi, respon dari peluncuran boad game Palagan sangat baik ditunjukkan dengan mendapatkan dukungan dari Satgas COVID Nasional bidang Perubahan Perilaku Masyarakat dan Pemerintah Provinsi Jawa Timur untuk didistribusikan kepada pihak-pihak yang berkaitan langsung dengan keluarga seperti Dinas Kesehatan yang berada di wilayah yang kurang terjangkau fasilitas komunikasi digital yang baik atau keluarga dengan anggota keluarga yang masih anak-anak dan menyukai permainan edukatif di wilayah perkotaan sebagai segmentasi khususnya.

Permainan papan Palagan dikembangkan menggunakan teknologi Augmented Reality (AR) sebagai fitur tambahan yang terdapat pada beberapa kartu, hal tersebut menjadi kekurangan dikarenakan konten pada objek augmented tidak fokus untuk menyampaikan informasi secara detail, pengguna hanya menemukan 10 objek augmented reality pada 10 kartu yang tersebar pada 7 tema elemen kartu sehingga informasi yang sudah didapatkan dari kartu dan mendapat respon baik belum dikembangkan untuk mendapatkan pengalaman belajar yang tuntas, dapat memicu antusiasme dan repetisi informasi dari penggunanya, sedangkan keunggulan dari aplikasi Augmented Reality adalah dapat menggugah minat dari penggunanya untuk belajar dan dapat membuat penggunanya merasa terhibur, objek augmented reality yang ditampilkan melalui perangkat seperti smartphone, tablet atau perangkat Head Mounted Display (HMD) dapat terasa lebih hidup [6]. Untuk mencapai keunggulan itu diperlukan perancangan pengembangan dari aplikasi Augmented Reality yang lebih mendetail, khususnya tentang protokol kesehatan dimana hal tersebut untuk meminimalisir kesenjangan kepatuhan penerapan protokol kesehatan pada usia anak-anak dibanding usia dewasa. Rumusan pada perancangan ini adalah bagaimana merancang aplikasi augmented reality bertema edukasi protokol kesehatan berbasis permainan papan yang sesuai untuk anak usia sekolah dasar, kontribusi dari penulisan perancangan ini adalah memetakan konten augmented reality bertema edukasi protokol kesehatan yang secara spesifik ditujukan untuk anak usia sekolah dasar.

\section{Metode Penelitian}

Metode penelitian yang digunakan pada perancangan ini adalah kajian literatur, studi produk terdahulu dan user persona, Pemanfaatan metode user persona adalah memahami

Perancangan Augmented Reality Media Edukasi Protokol Kesehatan Berbasis Permainan 
kebutuhan pengguna untuk merancang aplikasi yang memberikan pengalaman pengguna yang baik [7], seperti dijelaskan pada bagan kerangka penelitian dibawah proses dimulai dari identifikasi masalah yang didapatkan data bahwa kesenjangan penerapan protokol kesehatan terjadi pada usia anak-anak, identifikasi masalah selanjutnya adalah sudah terdapat produk terdahulu sebagai media komunikasi terhadap anak-anak mengenai pandemi Covid 19 berupa boardgame yang bernama Palagan, identifikasi masalah berikutnya adalah boardgame Palagan belum mengolah konten informasi augmented reality-nya dengan baik untuk mendapatkan pengalaman belajar yang maksimal mengenai protokol kesehatan, setelah mengidentifikasi masalah dirumuskanlah menjadi satu rumusan perancangan yaitu bagaimana merancang aplikasi augmented reality bertema edukasi protokol kesehatan berbasis permainan papan yang sesuai untuk anak usia sekolah dasar, dari rumusan tersebut dilakukan kajian terhadap pustaka atau sumber-sumber tertulis mengenai augmented reality yang digunakan sebagai media edukasi, analisa hasil kajian dari sumber tertulis ditambahkan dengan analisa hasil kajian produk terdahulu yaitu aplikasi Palagan yang dapat diunduh bebas di platform marketplace Google Play, hasil kedua analisa ditambahkan dengan analisa user persona dari perancangan aplikasi Augmented Reality ini sehingga didapatkan hasil luaran perancangan yang komprehensif atau mendekati harapan, keinginan dan kebutuhan sebenarnya dari pengguna aplikasi augmented reality dan dilakukan pengujian kepada penggunanya sehingga didapatkan kesimpulan dan saran yang relevan dari perancangan aplikasi.
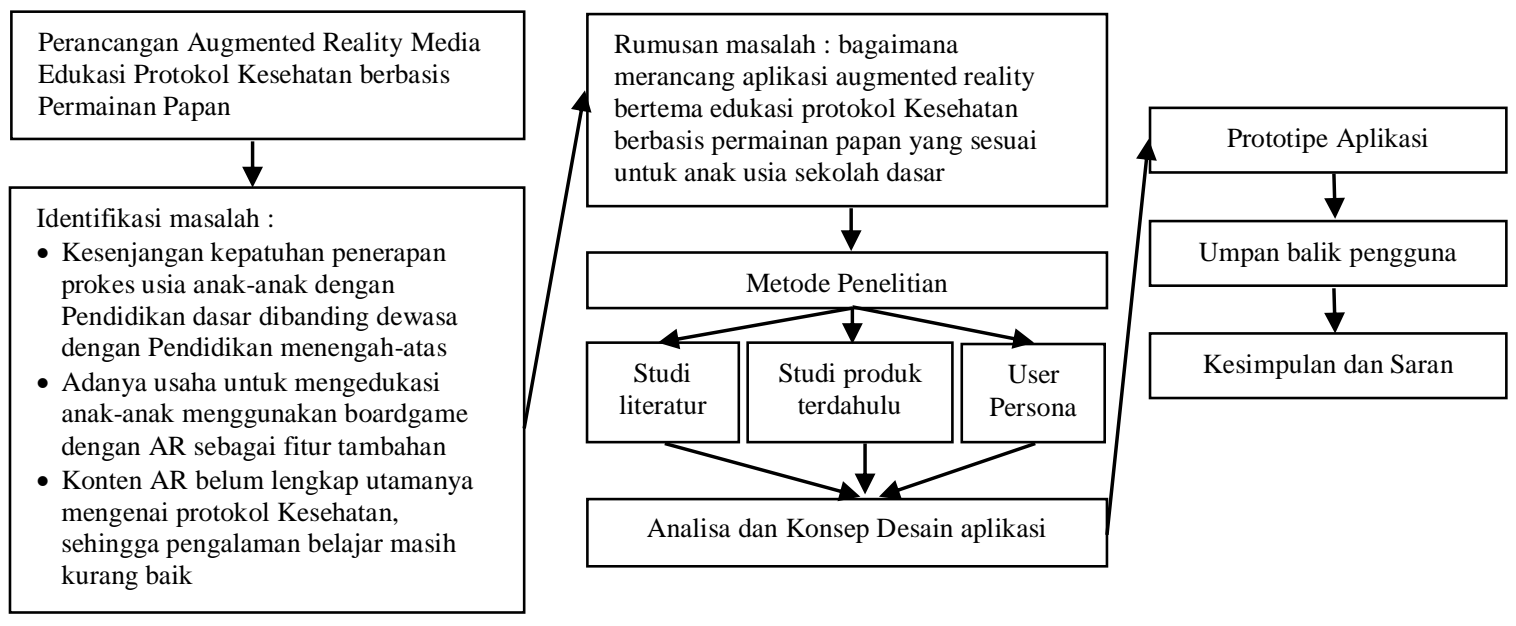

Bagan 1 kerangka penelitian

\section{Hasil dan Pembahasan}

\subsection{Hasil Studi Literatur}

Hasil analisa dari studi literatur yang sudah dilakukan adalah para perancang atau pengembang Augmented Reality (AR) yang berisikan konten edukasi wajib menentukan produk AR yang tepat sasaran supaya proses belajar dapat berjalan dengan baik, para perancang atau pengembang wajib memahami bagaimana menciptakan pengalaman belajar yang terintegrasi dengan pedagogi belajar formal seperti di sekolah atau belajar melalui kurikulum yang ada, contohnya adalah aplikasi AR yang terkoneksi dengan buku pembelajaran [8], artinya pengembang AR akan lebih efektif jika tidak membuat aplikasi yang berdiri sendiri sebagai marker dari aplikasi AR, akan lebih baik jika marker adalah sesuatu yang terintegrasi dengan aktivitas yang sudah dilakukan oleh penggunanya. Hasil analisa lain dari studi literatur adalah anak usia sekolah lebih memilih metode pembelajaran menggunakan AR yang lebih menstimulasi dan menarik daripada menggunakan slide persentasi [9] artinya anak usia sekolah lebih menyukai kegiatan belajar yang berbasis 
praktikum sehingga anak bebas untuk bereksperimen. Hasil analisa lainnya dari kajian literatur adalah jarak ideal kamera perangkat dengan marker supaya mampu memunculkan visual dengan baik adalah 14-25 cm dengan kondisi pencahayaan yang baik [10].

\subsection{Hasil Studi Produk Terdahulu}

Produk aplikasi AR Palagan yang diluncurkan pada tahun 2020 di google play merupakan produk yang terintegrasi dengan permainan papan Palagan yang didistribusikan kepada Dinas Kesehatan di Jawa Timur, hingga bulan Oktober 2021 aplikasi tersebut mendapatkan review bintang 5 atau aplikasi yang baik menurut penggunanya, aplikasi tersebut telah diunduh lebih dari 1000 pengguna, kelebihan dan kekurangan pada aplikasi AR Palagan dideskripsikan pada tabel 1 dibawah ini.

\begin{tabular}{|l|l|}
\hline \multicolumn{1}{|c|}{ Kelebihan aplikasi } & \multicolumn{1}{|c|}{ Kekurangan aplikasi } \\
\hline $\begin{array}{l}\text { Aplikasi stabil pada android versi 4.4 hingga } \\
\text { android versi 11 }\end{array}$ & Aplikasi berukuran cukup besar hingga 134 MB \\
\hline $\begin{array}{l}\text { Konten rating aplikasi sesuai dengan target } \\
\text { pengembang yang menyasar anak-anak usia } \\
\text { dibawah 12 tahun dan mendapat raring 3+ } \\
\text { dari IARC (International Age Ratings } \\
\begin{array}{l}\text { Coalition) } \\
\text { Aplikasi didukung distribusi permainan } \\
\text { papan yang baik dan sudah dikenal }\end{array}\end{array}$ & $\begin{array}{l}\text { Dari 58 ilustrasi keseluruhan kartu terdapat 15 } \\
\text { protokol kesehatan terdapat 3 kartu yang terdapat } \\
\text { objek AR }\end{array}$ \\
\hline $\begin{array}{l}\text { Sampel permainan papan Palagan dapat } \\
\text { diunduh bebas pada tautan deskripsi di } \\
\text { Google Play }\end{array}$ & $\begin{array}{l}\text { Aplikasi dimainkan tanpa tambahan narasi pada } \\
\text { objek AR }\end{array}$ \\
\hline
\end{tabular}

Tabel 1 kelebihan dan kekurangan aplikasi AR Palagan

\subsection{Hasil User Persona}

Tipikal pengguna yang disasar oleh aplikasi AR dalam perancangan ini adalah pengguna dengan demografi berusia antara 6 hingga 12 tahun, berjenis kelamin laki-laki atau perempuan, memiliki minat tinggi terhadap permainan yang melibatkan aktivitas motorik, memiliki perhatian terhadap hal-hal yang baru, memiliki dukungan dari orang tua berupa pendampingan terhadap aktivitas kesehariannya, memiliki akses untuk memainkan perangkat smartphone atau tablet berbasis android yang dimiliki sendiri atau meminjam orang tuanya, memiliki minat membaca yang baik, senang dengan cerita fiksi atau fiksi ilmiah, memiliki rasa penasaran yang tinggi yang ditunjukkan dengan ungkapan pertanyaan yang kritis terhadap keluarga atau orang tuanya, berada pada lingkungan keluarga yang rata-rata berpendidikan menengah keatas dan orang tua yang berpenghasilan sedikit diatas upah minimum regional di wilayah tempat tinggalnya yang memiliki keterbukaan pemikiran dan mengikuti perkembangan teknologi.

\begin{tabular}{|c|l|}
\hline & \multicolumn{1}{|c|}{ Ciri persona } \\
\hline Putra & Memiliki akses gadget dari orang tua \\
\hline &
\end{tabular}

Tabel 2 user persona segmentasi aplikasi AR 


\subsection{Konsep Desain dan Prototipe Aplikasi}

Dari hasil analisa yang sebelumnya sudah dilakukan maka disusun kedalam visualisasi fishbone untuk memetakan konsep visual dan komunikasi yang diusung pada perancangan aplikasi ini, bagan 2 berikut merupakan deskripsi dari konsep visual dan komunikasi :

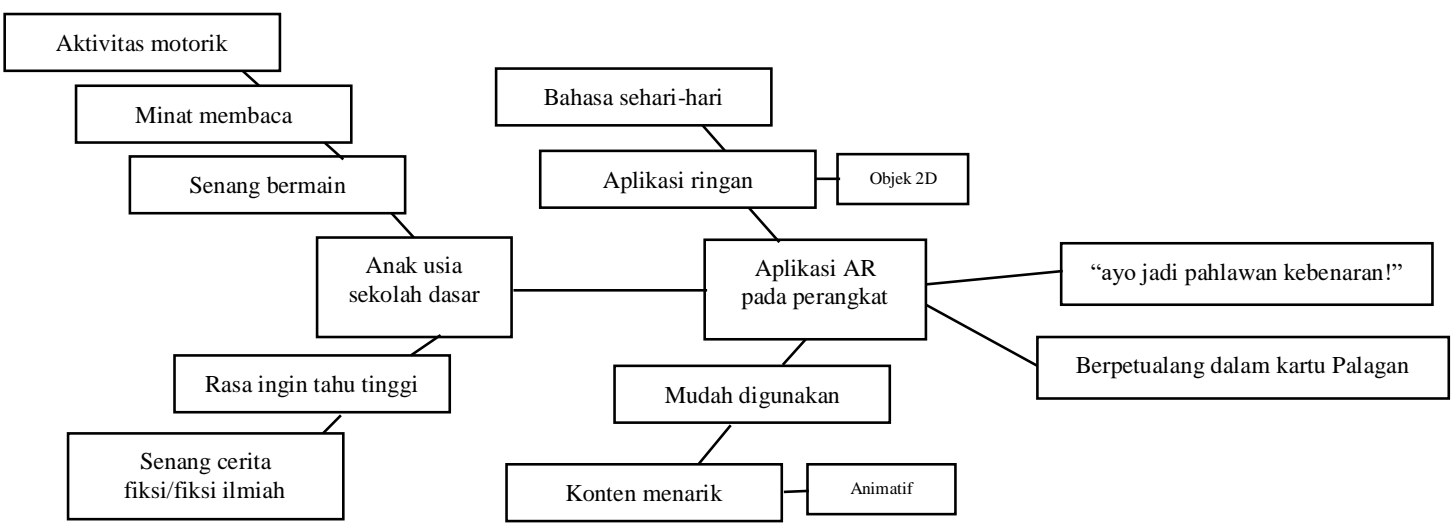

Bagan 2 diagram konsep visual dan komunikasi

Konsep komunikasi yang diangkat adalah ayo jadi pahlawan kebenaran, dengan konsep ini anakanak diajak untuk bermain dan belajar untuk mencari yang mana adegan AR dari kartu yang menunjukkan protokol kesehatan yang benar, secara default objek AR diatur supaya menunjukkan protokol kesehatan yang keliru dan mengatur waktu supaya anak untuk menonton adegan yang keliru tersebut, selang beberapa waktu akan keluar tombol virtual yang apabila dipencet oleh anak-anak maka akan keluar adegan protokol yang benar. Karena aplikasi AR ini terintegrasi dengan papan permainan Palagan maka ketika anak-anak memainkan kartu protokol ini maka posisi anak tersebut mendapatkan skor tambahan dan pemain dapat disebut sebagai pahlawan atau bersikap heroik dengan menjaga protokol kesehatan.

Protokol kesehatan yang divisualisasikan dalam objek augmented reality animasi adalah:

1. Protokol jaga jarak

2. Protokol buang masker

3. Protokol cuci tangan tangan pakai sabun

4. Protokol bersihkan benda dengan disinfektan

5. Protokol ibadah

6. Protokol hindari kerumunan

7. Protokol pembelajaran jarak jauh

8. Protokol selalu bermasker

9. Protokol kerja dari rumah

Terdapat item protokol yang dijadikan satu dengan protokol yang sudah disebutkan diatas, dikarenakan kemiripan protokol atau merupakan satu rangkaian aktivitas seperti protokol cuci muka, protokol hindari menyentuh wajah dan protokol mandi, ketiga tersebut merupakan satu rangkaian aktivitas setelah melakukan protokol mencuci tangan pakai sabun, artinya jika belum mencuci tangan pakai sabun agar dihindari langsung mencuci muka, menyentuh wajah dan mandi.

Konsep visualisasi objek AR dari kartu protokol kesehatan menggunakan animasi 2D berframe rate 15, objek AR yang tampak dikunci posisinya untuk selalu menghadap kamera 
perangkat sehingga tampilan dari objek akan selalu utuh tampak depan jika dilihat dari layar perangkat, hal ini dilakukan untuk menghindari terjadinya bug atau kesalahan animasi dan menambah imersifitas dari objek AR itu sendiri seperti ditunjukkan pada gambar 1 dibawah.

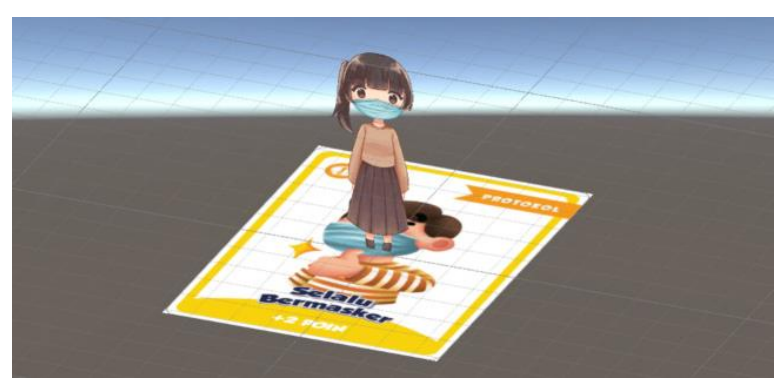

Gambar 1 layout objek AR terhadap marker

Animasi yang disajikan menggunakan konsep adegan benar dan adegan salah, hal ini disajikan sebagai pembelajaran bagi anak-anak, dimana sesuai analisa dari user persona anakanak usia sekolah dasar memiliki rasa ingin tahu yang tinggi, mereka dilatih untuk berpikir jika protokol adegan salah adalah seperti yang tampak maka bagaimana dengan protokol adegan benar, dari konsep tersebut dimungkinkan mereka untuk bernalar dan memicu inisiatif untuk bertanya kepada orang tua atau keluarganya tentang penerapan protokol kesehatan disekitar mereka. Seperti ditunjukkan pada gambar 2 dan 3 yang merupakan sekuen gerakan dari karakter yang memerankan adegan protokol kesehatan dimana karakter divisualisasikan dengan gaya visual ilustratif deformatif yang mengubah proporsi ukuran anggota badan seperti kepala yang berukuran lebih besar dari ukuran normal sehingga karakter tampak lucu.
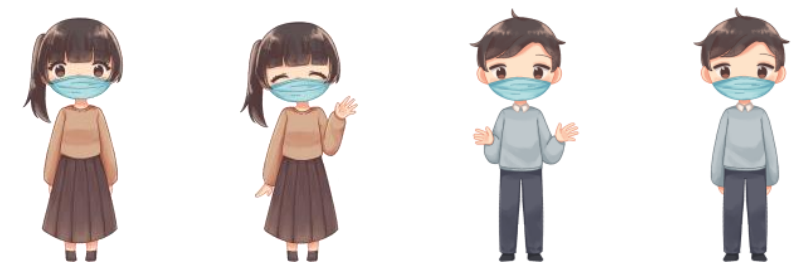

Gambar 2 protokol kesehatan adegan ketika menjaga jarak yang benar

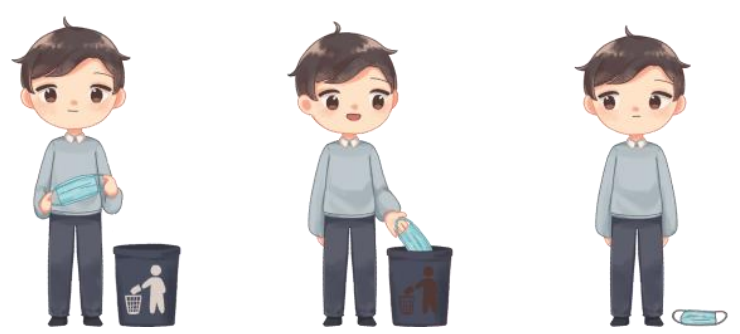

Gambar 3 sekuen protokol membuang masker yang benar dan salah 


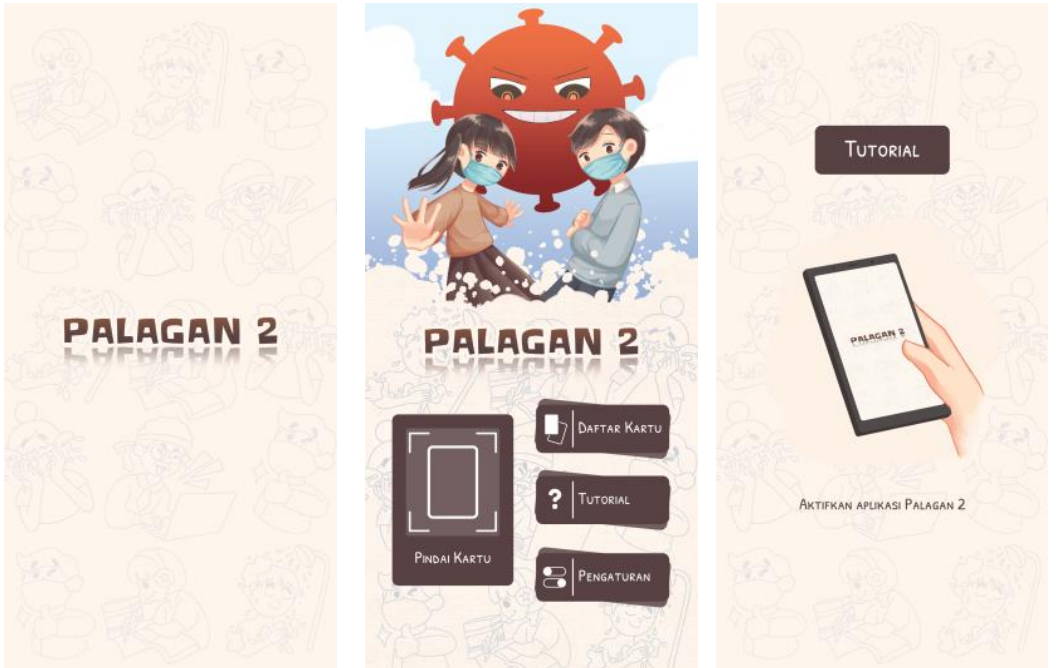

Gambar 4 tampilan halaman splashscreen dan menu utama dari aplikasi Palagan 2

Pada gambar 4 menunjukkan halaman splashscreen untuk awalan dan antarmuka dari halaman utama aplikasi, ukuran tombol dibuat besar dan menggunakan bahasa indonesia untuk memudahkan anak-anak dalam menggunakan aplikasi AR, terdapat 4 menu utama yaitu pindai kartu, daftar kartu, tutorial dan pengaturan. Fitur menu pindai kartu apabila diakses maka perangkat akan memulai untuk mode memindai marker kartu dengan mengaktifkan kamera belakang dari perangkat, fitur menu daftar kartu digunakan untuk melihat kartu-kartu apa yang dapat dipindai oleh aplikasi AR ini, utamanya adalah semua kartu protokol kesehatan, adapun untuk kartu protokol cuci muka, menyentuh wajah dan mandi memiliki konten objek AR yang sama dengan protokol cuci tangan. Fitur menu tutorial digunakan untuk menginformasikan cara penggunaan, cara penggunaan disajikan dengan menggunakan gambar ilustrasi dan suara sehingga anak-anak dapat dengan mudah menirukannya apabila kesulitan menggunakan aplikasi untuk pertama kalinya, dan fitur menu pengaturan digunakan untuk mematikan suara musik atau suara narasi dari aplikasi AR.

\subsection{Umpan Balik Pengguna}

Prototipe aplikasi diujikan kepada 30 responden anak-anak berusia 6-12 tahun atau usia sekolah dasar yang diambil secara acak tanpa melihat jenjang kelas sekolah dasar, jenis kelamin, dan bertempat tinggal di wilayah kota besar di jawa timur, digunakan skala likert untuk mengukur pengalaman dari responden dimana skor 1 untuk penilaian sangat buruk/sangat tidak setuju dan skor 5 untuk penilaian sangat baik/sangat setuju. Terdapat 5 item pertanyaan kepada responden, daftar pertanyaannya adalah sebagai berikut :

1. Apakah aplikasi mudah digunakan dari awal hingga akhir?

2. Apakah animasi objek terlihat dengan baik dan jelas?

3. Apakah pesan dalam animasi mudah dimengerti maksudnya?

4. Apakah aplikasi mudah digunakan untuk memindai kartu protokol kesehatan?

5. Apakah aplikasi berjalan dengan baik tidak ada adgen animasi yang tersendat / bug?

6. Apakah pesan hidup sehat dalam permainan Palagan dapat ditemui dalam kehidupan sehari-hari?

7. Apakah mudah menirukan pesan hidup sehat dalam permainan AR Palagan dalam keseharian baik disekolah, dirumah atau ketika diluar rumah?

Dari hasil penghitungan didapatkan bahwa $60 \%$ anak-anak sangat setuju bahwa aplikasi mudah digunakan oleh mereka ketika bermain kartu atau tidak bermain kartu mainan Palagan, tidak bermain kartu dalam artian mereka memindai kartu sebagai marker namun tidak memainkan 
permainan Palagan. Didapatkan data $80 \%$ aplikasi sangat mudah mengenali kartu protokol kesehatan sebagai marker dari objek AR, terdapat $20 \%$ anak-anak yang merasa bahwa pesan dari animasi cukup mudah dimengerti dan $20 \%$ mudah mengerti pesan dari animasi, hal ini dikarenakan daya tangkap pemahaman terhadap sebuah pesan berbeda-beda tergantung dari kreativitas dan intelektualitas masing-masing anak, dapat juga dikarenakan ketidak jelasan gerakan dari animasi dikarenakan layar dari perangkat berukuran relatif kecil atau kurang dari 6 inch.

\begin{tabular}{|c|c|c|c|c|c|}
\hline Pertanyaan & Skor STS & Skor TS & Skor R & Skor S & Skor SS \\
\hline P1 & 0 & 0 & 4 & 8 & 18 \\
\hline P2 & 0 & 1 & 5 & 9 & 15 \\
\hline P3 & 0 & 2 & 7 & 9 & 12 \\
\hline P4 & 0 & 0 & 0 & 6 & 24 \\
\hline P5 & 0 & 0 & 5 & 11 & 14 \\
\hline P6 & 0 & 0 & 0 & 4 & 26 \\
\hline P7 & 0 & 0 & 0 & 11 & 19 \\
\hline
\end{tabular}

Tabel 2 rekapitulasi hasil umpan balik dari pertanyaan

\section{Kesimpulan}

Dari hasil pengujian pengguna dan pengamatan pada proses pembuatan prototipe aplikasi, didapatkan kesimpulan antara lain :

1. Dengan menggunakan metode user persona hasil dari rancangan aplikasi mendapatkan respon mudah dipahami pesannya oleh lebih dari 70\% anak-anak berusia Sekolah Dasar.

2. Dengan memberi ruang lingkup permasalahan menjadi terfokus pada isu protokol kesehatan, beban informasi yang diterima oleh anak berusia sekolah dasar menjadi terkelola dengan baik, terbukti dengan lebih dari $70 \%$ anak memahami alur cerita yang disampaikan melalui aplikasi AR

3. Dengan menggunakan kombinasi media belajar melalui permainan papan dan aplikasi augmented reality menjadikan anak menjadi lebih kreatif dan memicu untuk berpikir kritis mengenai tindak perilaku sosial mereka dalam kehidupan sehari-hari.

\section{Referensi}

[1] Yatimah Durotul, Kustandi C, Maulidina Azmira, Irnawan Fernanda, Andinnari Rasidha S. Peningkatan Kesadaran Masyarakat tentang Pencegahan COVID-19 berbasis Keluarga dengan Memanfaatkan Motion Grafis di Jakarta Timur. Jurnal Karya Abdi. 2020; Vol 4 No 1. ISSN:2580-2178

[2] Afrianti Novi, Cut Rahmiati. Faktor-Faktor Yang Mempengaruhi Kepatuhan Masyarakat Terhadap Protokol Kesehatan Covid-19. Jurnal Ilmiah Permas STIKES Kendal. 2021;Vol 11 hal 113-124. ISSN 2549-8134

[3] Susan L. Cutter, Bryan J. Boruff and W. Lynn Shirle, Social Vulnerability to Environmental Hazards. 2003; vol. 84. 244

[4] Rismawati. Menstimulus perkembangan dan kecerdasan otak anak dengan permainan. 2002. Jakarta: 12.

[5] Ramadhani Nugrahardi, Yudistira Alamin Rabendra, Purwarupa Papan Permainan Bertema Global Pandemic Sebagai Upaya Edukasi Bencana Kesehatan Menggunakan Simulasi Augmented Reality. Jurnal Kartala. 2020;Vol. 1 No 1. ISSN 2580-9997 
[6] B. A. Suryawinata, "Pemanfaatan Augmented Reality Dalam Memvisualisasikan Produk Perumahan Melalui Internet," ComTech: Computer, Mathematics and Engineering Applications, vol. 1, no. 2, p. 758, Dec. 2010, doi: 10.21512/comtech.v1i2.2583

[7] Kusuma Andhyka Wahyu, Kharisma Muzaki Ghufron, Fauzan. Penggunaan User Persona Untuk Evaluasi dan Meningkatkan Ekspektasi Pengguna Dalam Kebutuhan Sistem Informasi Akademik. Jurnal Sintech. 2020; Vol 3 No 2. ISSN 2598-9642

[8] I. Radu, 'Augmented reality in education: A meta-review and cross-media analysis', Pers. Ubiquitous Comput., 2014; vol. 18, no. 6, pp. 1533-1543

[9] S. C.-Y. Yuen, G. Yaoyuneyong, and E. Johnson, 'Augmented Reality: An Overview and Five Directions for AR in Education', J. Educ. Technol. Dev. Exch., 2011; vol. 4, no. 1

[10] Oktoverano Lengkong, Andria Wahyudi, Riven Lumangkun, Mitchella Polimpung. Perancangan Aplikasi Animasi Interaktif Cerita Alkitab Dengan Menggunakan Teknologi Augmented Reality Berbasis Android. Cogito Smart Journal. 2020;Vol. 6 No.1. ISSN: 2477-8079 